\title{
Developing Approach for Conception of Appropriate Business Model for Distributed Business Information Systems
}

\author{
Evan Asfoura, Mohammad Samir Abdel Haq \\ Dar Al Uloom University \\ Riyadh, Saudi Arabia
}

\begin{abstract}
In the last few years, business in internet has become more and more significance. On other hand new development of internet technology is rapid and changed every day. Thus Business models have to be continually adapted to meet the requirements of new business ideas. One of these new and important business ideas is; how to supply the needs of small and medium sized enterprises (SME) with business software (E.g. Enterprise resource planning System $(E R P))$
\end{abstract}

\section{Introduction}

An ERP system is a standard software system which provides functionalities to integrate and automate the business practices associated with the business process of a company. The integration is based on a common data model for all system components and extents to more than one enterprise sectors [2], [12], [18] and [19]. The increasing number of the small and medium companies' employees, extended the need for flexible functionalities in ERP systems. SMEs face different problems when they buy the ERP systems, like [1] and [7].

- Not all installed components are needed.

- The usage of licenses, Administration, and maintenance of these products are too expensive.

- Normally, ERP systems are complex and overloaded with stuff, functions and options, therefore it is hard for new user to learn.

- High-end Hardware is required.

Therefore, in the last few years the idea of the Federated ERP-System in the basis of Web-Services has evolved. A federated ERP system (FERP system) is an ERP system which consists of system components that are distributed within a computer network. The overall functionalities are provided by an ensemble of allied network nodes that all together appear as a single ERP system to the user. Different ERP system components can be developed by different vendors [1], [7] and [8]. Through the FERP system, companies pay only for components deemed necessary. Also, the needed End-Hardware is made available by the service provider which in turn, reduces costs [7].
An ERP system component in this case is reusable, closed and marketable software module which provides services over a well-defined interface. These components can be combined with other components in an unpredictable manner [25]. Those components are described, published and used as Web services.

A web service is a software system designed to support interoperable machine-to-machine interaction over a network. It has an interface described in a machine-processable format (specifically WSDL). Other web systems interact with the web services in a manner prescribed by its description using SOAP-messages typically conveyed using HTTP with an XML serialization in conjunction with other web-related standards [27]. The search for these services by FERP Systems is covered by the functionality which is considered as the logical and stable construction stone in ERP system [7].

The phases of FERP scenario are divided into two processes:

- Production process includes the isolation of ERP components, description, publishing those components as web services through the web standards and the integration of these web services in FERP workflows.

- Marketing process includes the Exchanging of ERP components as web services need through a suitable business model. Therefore, businesses should be adopted to fulfill the new idea's need.

A Business model involves [24]:

- The architecture for the product, service and information flows.

- The business actors, their roles, their potential benefits from the business model, and the revenue streams.

In the second section of this work we will define five relevant characteristics and their attributes and summarize it in one table. In third section we will present a developing approach which can lead us to an appropriate business model for distributed ERP systems. This approach runs over three phases; Characterization, adapting and goal phase. In this paper we will focus on the first phase; Characterization This work will be summarized in the fourth section. 


\section{Characteristics and Attributes}

By researching the literature on this topic, we have identified three relevant characteristics and their attributes that are suitable for the partial economical characterization of this business model. Through these characteristics and their attributes, one can answer the following questions (see table 1) [3]:

- In which domain is this business model applicable?

- Which type of goods can be exchanged through this business model?

- To which extent will this business model integrate into the Internet-economy?

- To which type of basis model does this business model belong to?

- What is the source of revenue of this business model? And what are the forms of this revenue?

There are many business models, e.g., business to business (B2B), business to customer (B2C), customer to customer (C2C), customer to business (C2B), administration to administration (A2A), administration to business (A2B), business to administration (B2A), etc. In this paper we will focus on the most popular models which are (B2B), (B2C) and $(\mathrm{C} 2 \mathrm{C}$ ) (for more details [3]. Not all products or goods can be traded alike through E-markets. There are many factors (related to the vendor or to the customer) that could affect the trading process [22]. These goods are divided into two categories: Material goods and Immaterial goods [15], [20] and [22].The integration's degree in the internet's economy depends on the ability to implement the transaction phases electronically.

Table 1. The Selected Characteristics and Their Attributes

\begin{tabular}{|c|c|c|c|c|c|c|c|c|}
\hline Charact- & \multicolumn{8}{|c|}{ Attributes } \\
\hline ID in IE & \multicolumn{4}{|c|}{ Full } & \multicolumn{4}{|c|}{ Partial } \\
\hline Business & \multicolumn{4}{|c|}{ B2B } & \multicolumn{3}{|c|}{$\mathrm{B} 2 \mathrm{C}$} & $\mathrm{C} 2 \mathrm{C}$ \\
\hline $\begin{array}{c}\text { Basic- } \\
\text { BM }\end{array}$ & \multicolumn{2}{|c|}{ Content } & \multicolumn{2}{|c|}{ Context } & & Conmerce & \multicolumn{2}{|c|}{ Cormection } \\
\hline \multirow{2}{*}{$\begin{array}{l}\text { Offered } \\
\text { Goods }\end{array}$} & \multicolumn{3}{|c|}{ Tangible Goods } & \multicolumn{5}{|c|}{ Irtamgble Goods } \\
\hline & $\begin{array}{c}\text { Physical } \\
\text { Goods }\end{array}$ & & $\begin{array}{l}\text { yysical } \\
\text { rvices }\end{array}$ & $\begin{array}{l}\text { Digi } \\
\text { Prody }\end{array}$ & & $\begin{array}{r}\text { Digital } \\
\text { Services }\end{array}$ & Information & $\begin{array}{l}\text { Special } \\
\text { Goods }\end{array}$ \\
\hline $\begin{array}{l}\text { Revervie } \\
\text { Sources }\end{array}$ & \multicolumn{3}{|c|}{ Products } & \multicolumn{3}{|c|}{ Cortacts } & \multicolumn{2}{|c|}{ Information } \\
\hline $\begin{array}{c}\text { Reverne } \\
\text { Foms }\end{array}$ & \multicolumn{2}{|c|}{$\begin{array}{l}\text { Direct and } \\
\text { Transaction- } \\
\text { dependert }\end{array}$} & \multicolumn{2}{|c|}{$\begin{array}{l}\text { Direct and } \\
\text { Tramsaction- } \\
\text { independent }\end{array}$} & $\& \mathrm{~T}$ & $\begin{array}{l}\text { Indirect } \\
\text { Transaction- } \\
\text { lependert }\end{array}$ & \multicolumn{2}{|c|}{$\begin{array}{l}\text { Indirect and } \\
\text { Transaction- } \\
\text { independert }\end{array}$} \\
\hline
\end{tabular}

Two forms are distinguished here: full and partial integration [3]. The relevant 4-basic business models types are "content", "connection", "commerce" and "context" [23] and [26]. The fact is that most of business models belong to one of the 4-Basics types.

A business model could be a hybrid of more than one type. 4-Basic types [16].

The sources of Revenue of business models fall into three categories: Products, contacts and information [21] and [26]. The forms of revenue were classified by Wirtz on one hand according to the players (i.e., buyers and sellers) into direct and indirect revenue and on the other hand according to the pricing conditions into transaction-dependent and transaction-independent [26]. In the next sections we will present approach for developing of appropriate business model for distributed ERP systems through logical steps.

\section{Developing Approach For Conseption of Appropriate Business Model for Federated ERP Systems}

Through the characteristics of business model which has been shown in the second section we present in the flowing Figure a developing approach which lead us to the appropriate concept for the exchange of FERP components as web services (see Figure 1). This developing approach consists of three phases every phase involves one or more of steps with the considering of the existent models, architectures and the special requirements of an FERP system.

The first phase is the characterization phase. In This phase we should answer the flowing three questions:

- Which business model type nowadays is existed and more suitable for FERP as a new Business idea?

- What could be provided in the expected business model?

- To which business fields belongs this business model?

These three questions can be answered and analyzed by using the characteristics "Business Fields", "Basic Business Models" and "Offered Goods" defined in Table 1.

Then this developing approach in Figure 1 is derived from the Table 1 . Table 1 serves information for classifying the existing business models. In contrary, the approach in Figure 1 presents basics phases for developing a new business model for a new business idea. The second phase (adapting phase) is added to identify the roles of the actors of the new models with considering the minimizing of 
the expected risks and problems which may be arise with these new ideas.

The expected results of this developing approach are a character-concept, role-concept and revenueconcept of an appropriate business model for FERP systems. In the flowing under sections we will present the first phase of this developing approach and we let the other phases as future works.

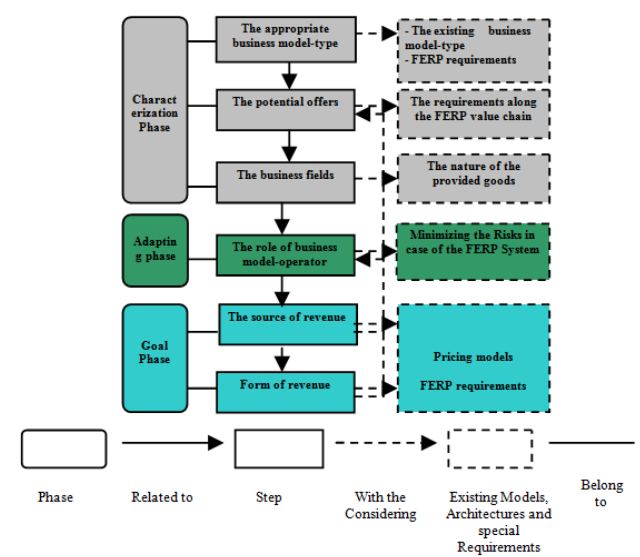

Figure 1. The developing approach for conception of business model for FERP systems

\subsection{Appropriate Type of business model for marketing of distributed ERP Systems}

An Enhanced and customized categorization of the business of the provider and facilitator in relation to the marketing of professional services and functionalities as Web Services in five forms [17]:

- The business model of software-companies, which offer services with obligatory fee for the direct revenue generating.

- The business model of software-companies, which offer in addition to the distribution and licensing of their software products free web services.

- Business models of companies that are not software vendors, but they offer free Web services to support their core business.

- Business models of companies whose core business is not in the production of software, but builds know-how solutions in these areas. These companies offer their Web services with obligatory fee.

- A new and customized business intermediaries for Web Services marketing is the broker (or brokerage), which mediates between Web services providers and the customer (enterprises, individuals, etc.) and supports the customers to find suitable Web services through online directory of services as a clear database. The Intermediary is an entity which stands between the seller and the customer and he can act towards both, in known or unknown ways. The importance of this element comes from reducing and facilitating the commercial and practical cost and the tow most famous examples are the E-mall and E-auction [5].

There are more than one customer and provider of the ERP components in case of FERP system. Due to the lack of pre-defined communication channels and areas of responsibility from enterprises and customers point of views, the determination and the direct contact of customers with multiple FERP service providers for adoption, customization and maintenance of such federated systems is very difficult and problematic. Therefore, this business model services as a commercial intermediary between the providers and customers. This intermediary presents the ERP components (ERP web services) of different providers and organizes a cross vendor to satisfy the functionality demanded by the customers [4].

In case of ERP auction, customer (user or company) should sign several contracts, if his/its requirements are covered by different ERP WS providers. That means that each provider is partially responsible to the user and there is no single "one" responsible party which customer could deal with in case of failure or any accident. As a result of this Problem, beside the high prices of ERPs software, we consider this possibility practically inapplicable. Then we can say that an ERP-mall as an intermediary business model between the providers and the end-customer (enterprise) is the reasonable and appropriate business model type [4].

After this primary determination we will characterize suitable offering form for this intermediary (mall), which can fulfill the needs of (SMEs) through an appropriate adaptation.

\subsection{The possible offers through FERP mall}

To characterize the FERP Mall, we will define the possible offers in case of FERP system. These offers depend on the requirements of FERP system. Figure 2 represents the requirements of FERP system along the value chain. In this context, we can distinguish between two categories of requirements [28]: Main and supporting requirements of FERP system. The characteristics of our FERP Mall could be achieved through the determination of the possible offers along the presented FERP value chain. We must determine who can offer which requirements of these? To determine that, we should classify all the requirements among the parties, that act in the market to exchange the ERP component. 


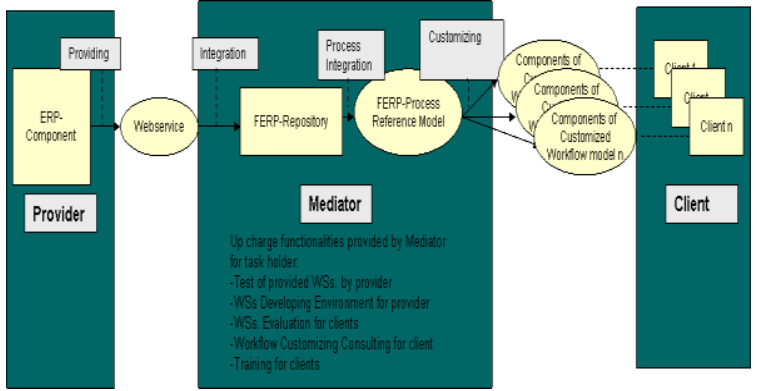

Figure 2. FERP Scenario (or FERP value Chain)

In the next sections we will present the possible distribution of offers between the three parties (providers (or developers), intermediaries and other parties). For the simplification here, the other parties represent other potential participants in the FERP market, who can offer just as the intermediary can do.

3.2.1. The Main requirements of FERP system. The main requirements are the necessary parts for the realization of FERP systems. This could be derived through the FERP scenario (or FERP value chain) to:

- FERP Web Services (FERP WSs): This web services are implemented by the suppliers (developers) and their interfaces are described by the WSDL-standard (WSDL = Web Services Description Language). These services are reusable and offer the FERP functionality as operations, which are required by user companies. The development of FERP WSs is open for all; therefore, any player could be as a FERP WSs developer in the market. The providers are responsible for the quality of FERP web services.

- WS-publishing: The WSs developers publish the WSDL interface descriptions in the online directories (repositories), which are structured by the UDDI standard (UDDI = Universal Description, Discovery and Integration). The main role of the FERP malls is as online directories provider, where providers can publish their FERP WSs and the customer enterprises can find the appropriate FERP WSs. FERP WSs in these repositories are classified based on the functional enterprise sectors (Accounting, Logistic... Sector) and every sector represent a different shop in our FERP Mall.

- ERP Workflow-Definitions (WF-Definitions): Workflow is a plan of sequential or in parallel chained functions as working steps in the mining of activities which lead to the creation or utilization of business [6]. By standardizing these types of activities in a workflow language (e.g. BPEL: Business Process Execution Language), it is possible to use workflow definitions in different companies, and to market it separately. FERP workflow combines Web services from different providers FERP for the support of the whole of FERP business process in user companies. Therefore, our FERP Mall appears as a provider of workflow reference model, which represents all possible scenarios (workflow descriptions) of a company. FERP mall can customize, through this reference model, the suitable workflow for each enterprise. FERP workflows can also be described by the user companies themselves, but in this case, FERP Mall is not responsible for the qualitative aspects of these workflows.

3.2.2. The Supporting requirements of FERP system. The supporting requirements here mean requirements which can support the FERP WS developers and the customer companies along the FERP value chain. These requirements can be offered either as fee-based services or as a free service to support the core business. In case of FERP systems, we can distinguish the following requirements:

- Web Services Developing Environment (WSDEnvironment): Because of the importance of Standardized Web Services description in case of the FERP systems, we can support the developers with tool which help them by the implementation of Web services. This tool (or development tool) could be used by standardizing the specification to describe functional and non-functional (qualitative) properties of Web services and to manage the development process for the reduction of development time and the potential errors by the WS development [11] and [14]. This tool is offered in FERP as service to be used by the developers, who seem to be costumers in this case.

- The Testing Services (T-Services): The intermediary (FERP Mall) offers web services test and Integration test for the user to find the error in the cooperation of various FERP Web Services [11]. This increases the intermediary safety in his relationships with the large number of FERP Web Services providers and increases the customers' trust in the reliability of the FERP systems. This test service could be offered by partners (third party) too.

- WS evaluation information (WSE-Information): FERP WSs are reusable products and every one could be provided from different developers with different prices quality levels. In our case the market is open to small and private developers for the development and offering of individual FERP WSs. In this situation the intermediary meets many risks because of the large number of foreign suppliers (developers). Therefore, the 
reputation of these developers has relevant role in increasing the trust and security between the intermediary and the providers (developers) and for the continuous assessment of the quality of a service. This has been considered in [10] and [8] through a secure protocol for exchange of the evaluation information between the provider, the customer, and a trusted third party. This collection and summarizing of historical evaluation information of FERP WSs is offered by intermediary (FERP mall) as trusted party as a quality - and safety information

- Consulting service: After the decision of the company to be a costumer of our FERP mall, we offer supporting advices to this company by selecting and adapting an appropriate FERP workflow. This consulting could play also important role for solving of the possible problems by the using of FERP system.

- Training service: the decision of the company to be a costumer by our FERP mall, the employees, who can use the FERP system. FERP Mall offers in FERP training courses to cover the lack of knowledge by using the new offers by external parts either.

In the last step in this phase we will discuss the business field of this business model according to the nature of the offers.

\subsection{Business fields of FERP Mall}

Table 2 shows a classification of the goods which are exchanged through the aimed FERP Mall between the actors.

Table 2. The Business Fields of FERP Mall

\begin{tabular}{|r|r|l|r|}
\hline goods & provider & costumer & $\begin{array}{r}\text { Business } \\
\text { field }\end{array}$ \\
\hline FERP WSs & $\begin{array}{r}\text { WS } \\
\text { Developer }\end{array}$ & $\begin{array}{l}\text { User- } \\
\text { Enterprise }\end{array}$ & X2B \\
\hline WF Definitions & Mediator & $\begin{array}{l}\text { User- } \\
\text { Enterprise }\end{array}$ & B2B \\
\hline WS Publishing & Mediator & $\begin{array}{l}\text { WS } \\
\text { Developer }\end{array}$ & B2X \\
\hline Environment & Mediator & $\begin{array}{l}\text { WS } \\
\text { Developer }\end{array}$ & B2X \\
\hline T Services & Mediator & $\begin{array}{l}\text { User- } \\
\text { Enterprise }\end{array}$ & B2B \\
\hline WS Evaluations & Mediator & $\begin{array}{l}\text { User- } \\
\text { Enterprise }\end{array}$ & B2B \\
\hline Consulting & Mediator & $\begin{array}{l}\text { User- } \\
\text { Enterprise }\end{array}$ & B2B \\
\hline Training & Mediator & $\begin{array}{l}\text { The } \\
\text { Employees } \\
\text { of } \\
\text { the } \\
\text { user- } \\
\text { Enterprise }\end{array}$ & B2C \\
\hline
\end{tabular}

„X"-letter in the business field column of this Table refers to anonym developer who develop the web services. We call it "Anonym developer" because the market in the case of FERP system is open for all the developers independent of their personalities.

The goals of all the relationships through FERP Mall are business goals. Every costumer invests by making business through buying of the offered goods from the provider. Therefore, all the relationships through this mall belong to B2B field. The relation by the offering of training for the employees of the customer enterprise seems as B2C but no cash flows because the user-enterprise pay for the training courses as part of its investment. Then this FERP mall is absolute B2B business model.

\section{Character-Concept of FERP Business Model}

As a result of this work is an FERP Mall. This mall offers FERP Web service through the online directory and work as an integrator of FERP WSs in FERP processes through workflow reference model, which provides all the possible scenario of business in an enterprise. This integrator can fulfill the needed FERP functionality as one hand and he is responsible to the user companies for the quality of ERP processes. The all FERP shops in FERP mall appear as single shop to the costumer companies, which supports all phases of transaction, but only the using of WS functionality execute directly between the FERP WS providers and the end-user. This mall also offers services (as service providers) which are needed for the marketing of FERP Web Services. These services appear in other shops (see Figure 3). All shops in the FERP Mall have a single shopping and payment system.

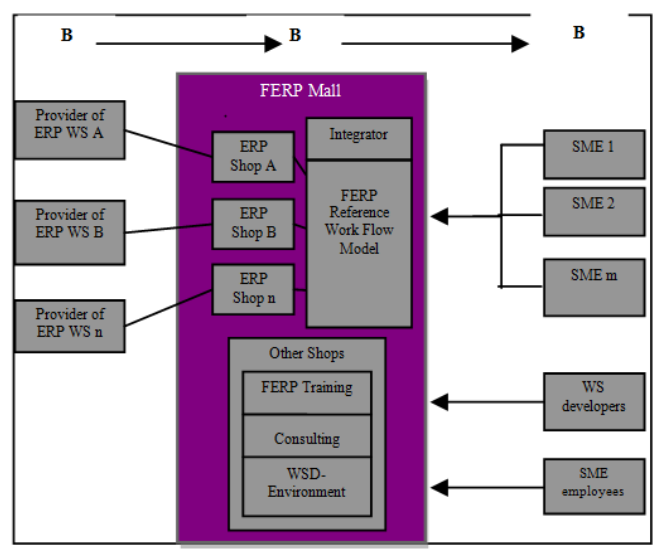

Figure 3. The character-concept of FERP Mall

In this work we have presented the first three steps from our developing approach. These steps represent the first phase (characterization-phase). Therefore, as feature work, we will discuss the role- 
concept of the FERP mall as mediator (intermediary) between the other parties and after that we can present the revenue-concept of this FERP mall as the last part of the presented developing approach for the conception of FERP business model.

\section{Conclusion}

In this paper we presented the FERP system as a new idea which cans fulfill the needs of the SME with low costs and solve more problems by these SME. After that we presented a developing approach which lead to the realization of the appropriate business model for exchange of FERP systems. This developing approach based on suitable characteristics and their attributes which has been chosen through the business model definitions by the literatures review. We have realized the first phase of this Approach that open the door for the farther developing of the other phases in the feature works. And this approach could be considered for the conception of appropriate business models for the new business idea especially for distributed information systems.

\section{References}

[1] Abels, S., Brehm, N., Hahn, A. and GÓmez, J. M.,: Change management issues in federated ERP-systems" An approach for identifying requirements and possible solutions. International Journal of Information Systems and Change Management (IJISCM), 1, pp. 318-335. (2006).

[2] Abts, D., and Mülder, W.: Grundkurs Wirtschaftsinformatik", Eine kompakte und praxisorientierte Einführung, 4. Aufl., Braunschweig et al. (2002).

[3] Asfoura E., Jamous, N. and Salem, W.: The economic classification of E-Learning business models, In: Institute of Electrical and Electronics Engineers: IEEE multidisciplinary engineering education magazine. - New York, NY: IEEE, Bd. 4, 1, S. 8-12 (2009).

[4] Asfoura, E., Jamous, N., Kassam, G. and Dumke, R.: E-mall as solution for marketing the federated ERP components on the basis of web services, In: International review of business research papers . - Melbourne, Bd. 5. 4, S. 478-490 (2009).

[5] Bartelt, A., and Lamersdorf, W.: Geschäftsmodelle des Electronic Commerce, in: Informatik - Wirtschaft und Wissenschaft in der Network Economy, pp. 902-908 (2001).

[6] Brehm, N., Gómez, J. M.: The Web Service-based combination of data and logic integration on Federated ERP systems, 18th IRMA International Conference Managing Modern Organizations with Information Technology, Vancouver, Canada (2007).
[7] Brehm, N, and Gomez, J. M.:Federated ERP-Systems on the basis of Web Services and P2P networks, International Journal of Information Technology and Management (IJITM), pp- 75-89 (2010).

[8] Brehm, N., and Gómez J. M.: Web Service-basierte Referenzarchitektur für Föderierte ERP-Systeme. In: (Pietsch, T.; Lang, C.V. Hrsg.): Ressourcenmanagement. Erich Schmidt Verlag, Berlin, pp. 125-142.1875 (2007).

[9] Brehm, N., Gómez, J. M. and Strack, H.: RequestResponse-Evaluation Infrastructure for trusted Web Service-based ERP systems, In: C. Rautenstrauch (Hrsg.), Die Zukunft der Anwendungssoftware - die Anwendungssoftware der Zukunft. Aachen: Shaker Verlag. pp. 83 - 93 (2007).

[10] Brehm, N, an J. M. Gómez, J.: Sicherheitsprotokoll zur Bewertung von Diensten in SOA-basierten Anwendungssytemen, in: BSOA Workshop Bewertungsaspekte Serviceorientierter Architekturen, Berlin (2006).

[11] Brehm, N., J. M. Gómez, J., and Ziesenitz, A.: Toolunterstützung bei der vermarktungsorientierten Entwicklung von Web Services als Bausteine komplexer betrieblicher Anwendungssysteme, in: proceeding of Multikonferenz Wirtschaftsinformatik, München/Garching (2008).

[12] Gronau, J, M.: Enterprise Resource Planning und Supply Chain Management, Archite-ktur und Funktionen. München (2004).

[13] Gomez, J. M., and Lübke, D.: in Kunzept und Support für das testen von Services, in: Orentierung für die Praxis. pp. 28-31 (2008).

[14] Höß, o., and Weisbeker, A.: konzeption eines Repositories zur unterstützung der wiederverwendung von Software-komponenten, in: Turowiski, k. (Hrsg.): 4.Workshop koponentenorentierte betriebliche Anwendungssysteme (WKBA). Augsburg, pp. 75-85 (2002).

[15]Maleri, R.: Grundlagen der Dienstleistungsproduktion, 3. vollst. ueberarb. Aufl., pp 50, Berlin (1994).

[16]Merz, M.: E-Commerce und E-Business Marktmodelle, Anwendungen und Technologien ,Kap. 3 dpunkt Verlag, Heidelberg (2001).

[17]Nüttgens, M.; Dirk, I.: Geschäftsmodelle für dienstbasierte informationssysteme- ein strategisservicesvon Webcher Ansatz zur Vermarktung, In: journal of Wirtschaftsinformatik, pp. 31-38 (2008).

[18]Rautenstrauch, C., Schulze, T.: Informatik für Wirtschaft-swissenschaftler und Wirtschaftsinformatiker, Berlin (2003).

[19] Robey, D., J. Ross, J, and Boudreau, M.: Learning to implement enterprise system, An exploratory study of the dialectics of change. Journal of Management Information Systems, pp. 17-46 (2002). 
[20] Scheer, C., and Loos, P.: Internetbasierte Geschäftsmodelle; Neue Möglichkeiten der Wertschöpfungsorganisation in der Internet-Ökonomie“" (2001).

[21] Skiera. B., and Lambercht, A.: Erlösmodelle im Internet, in Herrmann, A., Albers, (Hrsg.), pp. 817 (2000).

[22] Stelzer, D.: Digitale Güter und ihre Bedeutung in der Internet-Ökonomi (2000).

[23] Tamm, G., and Köhler T. R.: Konzepte in ECommerce - Anwendunge. in ISBN 3-935539-66-5 ), Berlin. pp. 43 (2004).

[24] Timmers, P.: Business Models for Electronic Markets". in: Electronic Markets 8(2) (1998).

[25]Turowski, K.: Fachkomponenten: Komponent enbasierte betriebliche Anwendungssysteme," Aachen (2003).

[26] Wirtz. B. W.: elechtronic Business“',-243, Wiesbaden (2001).

[27] W3C., 2003. Web service architecture, working Group note, im WWW unter http://www.w3.org/TR/wsarch /wsa.pdf (15.03.2008).

[28]Asfoura, E., Kassem, G. and Dumke, R.:.Characterization of business model for federated ERP systems, in: International Journal of $\mathrm{u}$ - and e-Service, Science and Technology Vol. 3, No. 4, December, 2010, S. 19-3 